\title{
Toxicity, Monitoring, and Biodegradation of Cypermethrin Insecticide: A Review
}

\author{
Ramandeep Kaur $\dagger$ and Joginder Singh \\ Department of Microbiology, Lovely Professional University, Phagwara-144411, Punjab, India \\ $†$ Corresponding author: Ramandeep Kaur; ramandeepk709@gmail.com
}

Nat. Env. \& Poll. Tech.

Website: www.neptjournal.com

Received: 14-03-2021

Revised: 13-05-2021

Accepted: 25-05-2021

Key Words:

Cypermethrin

Pyrethroid

Insecticide

Biodegradation

Toxicity

\begin{abstract}
Cypermethrin insecticide is widely used to prevent and control pest and crop diseases though, its residues have caused significant damage to the environment and living organisms. Microbial remediation becomes a popular approach to counter the toxicity of cypermethrin in both aquatic as well as terrestrial life. Cypermethrin can be effectively degraded to nontoxic compounds by bacterial and fungal strains. Various bacterial and fungal strains such as Ochrobactrum lupini DG-S-01, Bacillus sp. strain SG2, Azoarcus indigens strain HZ5, Streptomyces aureus strain HP-S-01, and Aspergillus oryzae M-4 are used for the cypermethrin degradation. Extensive usage of cypermethrin has caused problems such as surface water contamination, reduced fertility of the soil, detrimental effects on soil microbiota and non-targeted species. Due to environmental concerns associated with the cypermethrin in groundwater and food products, there is a crucial need to develop economical, rapid, and reliable techniques that can be used for field applications. An in-depth understanding of cypermethrin is explored in this review paper and possible solutions to mitigate its environmental toxicity are suggested.
\end{abstract}

\section{INTRODUCTION}

In India, crop production is increased with the usage of pesticides, however, increased usage of pesticides resulted in affecting adversely the aquatic ecosystem and selected body parts of non-target organisms (Agarwal \& Shahi 2015, Singh et al. 2010). Cypermethrin has been classified by WHO as a slightly hazardous type II pesticide (WHO 1994-95). Cypermethrin insecticide has more commercial applications in agriculture as well as domestic products (Zhang et al. 2011). Mostly when cypermethrin is degraded it breaks down into various metabolites such as 3-PBA. In India, cypermethrin is registered by CIBRC for use in eight specified crops, such as cabbage, wheat, cotton, rice, sugarcane, brinjal, sunflower, and okra. In India, the cypermethrin production appeared to be 6.5 MT in 2005-2006 and 2473 MT during 2009-2010. (State of Pesticide Regulations in India 2013) Cypermethrin is frequently used by Indian farmers to prevent insects in jute, wheat, paddy, and vegetables (Tendulkar \& Kulkarni 2012). Nontarget organism like L. marginalis (Raksheskar 2012, Pugazhendy et al. 2012, Pankaj et al. 2015) was reported to be more vulnerable to cypermethrin toxicity than the target organisms. During monsoon, the agricultural runoff loaded with cypermethrin contaminates the natural habitat of $L$. marginalis. Thus they are exposed to cypermethrin present in their natural habitat. Cypermethrin toxicity was recorded in West Bengal by different workers including (Raghavendra et al. 2014, Goswami et al. 2013). Even at very low concentration pyrethroids are highly effective, therefore, it is the most important pesticide. They are used against flies, mosquitoes, stored grain insects, and aphids. They are mostly used for pest controlling and eradicating the disease-causing vector in developing countries such as China (Chen et al. 2011a). Synthetic pyrethroids have been used in agricultural fields to control pests on a variety of crops for over 20 years. They gained popularity, however, after the use of cholinesterase inhibitor insect repellents was banned completely (Zhang et al. 2011). Although cypermethrin is an effective pesticide, it is toxic to non-targeted creatures. As a result, reducing the environmental impact of cypermethrin, as well as the risks to human health, is critical. Among various approaches, the biological approach is a more effective and promising strategy. And in this review, we have summarized the data available regarding the toxicity and degradation of cypermethrin which will help further help others to know about the different microbes involved in the bioremediation of cypermethrin.

\section{TOXICITY OF CYPERMETHRIN ON NON- TARGETED ORGANISMS}

Cypermethrin has shown toxic effects against various aquatic organisms like fish, daphnia, mussel, etc., goats, lizards, and human cells (Akinrotimi et al. 2012, Chen et al. 2016, Dawar et al. 2016). Cypermethrin adversely affects the central nerv- 
ous system (Tallur et al. 2008), leads to endocrine toxicity (Jin et al. 2011a), tumor promoter (Chen et al. 2011b), and has an immuno-toxic effect (Jin et al. 2011b) in nontargeted species. In females, several oral intakes of cypermethrin have shown detrimental effects on the uterus and ovaries and lead to loss of oocytes and follicular cells in ovaries formed by cypermethrin at the dosage of $20 \mathrm{mg} \cdot \mathrm{kg}_{\text {.day }}{ }^{-1}$ (Grewal et al. 2010). A reduction in mass of ovaries was detected after 4 weeks of cypermethrin intake although the length and weight of uterus and myometrium thickness improved at the dosage of $50 \mathrm{mg} \cdot \mathrm{kg}^{-1}$ body mass at 2 and 4 weeks (Sangha et al. 2013). The liver plays an essential role in the detoxification and decomposition of harmful chemicals like pesticides. In the removal of metabolic wastes from the body, the kidney plays a significant role. But cypermethrin has been shown to cause toxicity in the liver and kidney (Sushma \& Devasena 2010).

\section{CypermethrinToxic Effect on Aquatic Life}

Cypermethrin is a broad-spectrum insecticide. Like the targeted species, it also kills the other beneficial insects and animals. Fish are particularly affected by cypermethrin (Stephenson 1982) (Fig. 1). When exposed to cypermethrin, the amount of lipid peroxidation and glutathione peroxidase was elevated in the gills, kidneys, and liver of the Cyprinus carpio fish (Meenambal et al. 2012). The superoxide dismutase
(SOD) and catalase activities were reported more when treated with cypermethrin Cyprinus carpio compared to untreated controls (Meenambal et al. 2012). It was stated that cypermethrin exposed fish have gradually lost antioxidant defense ability along the exposure time. The authors reported the first evidence of cypermethrin-induced glutathione-S-transferase activity in a crustacean specimen. Cypermethrin treatment resulted in a reduction in the glycogen content of gill, mantle, foot, and gonads of clams Marcia opima (Tendulkar \& Kulkarni 2012). Nowadays, for ecotoxicological studies organism models are used for studying pesticide toxicity. In the aquatic environment, fish, mollusks, and amphibians (Johnson et al. 2017) are used as model organisms. Amphibians are considered as good indicators as they have a biphasic cycle and they encounter pesticides in both aquatic and terrestrial environments. As compared to larvae, the embryos were more resistant to cypermethrin. During embryo mobility assays, it was observed that cypermethrin causes spasmodic contractions (Macagnan et al. 2017). Cypermethrin deposits were recently detected in soil and water, and it poses a possible threat to aquatic species and humans (Kuivila et al. 2012). Alpha cypermethrin has a chronic toxic effect on channa fish. Lactate dehydrogenase (LDH), catalase, DNA, RNA, and protein have been investigated in the liver, gills, skeletal muscles, and brain of the Channa punctatus freshwater fish (Tripathi \& Singh 2013). In another research on zebrafish, a

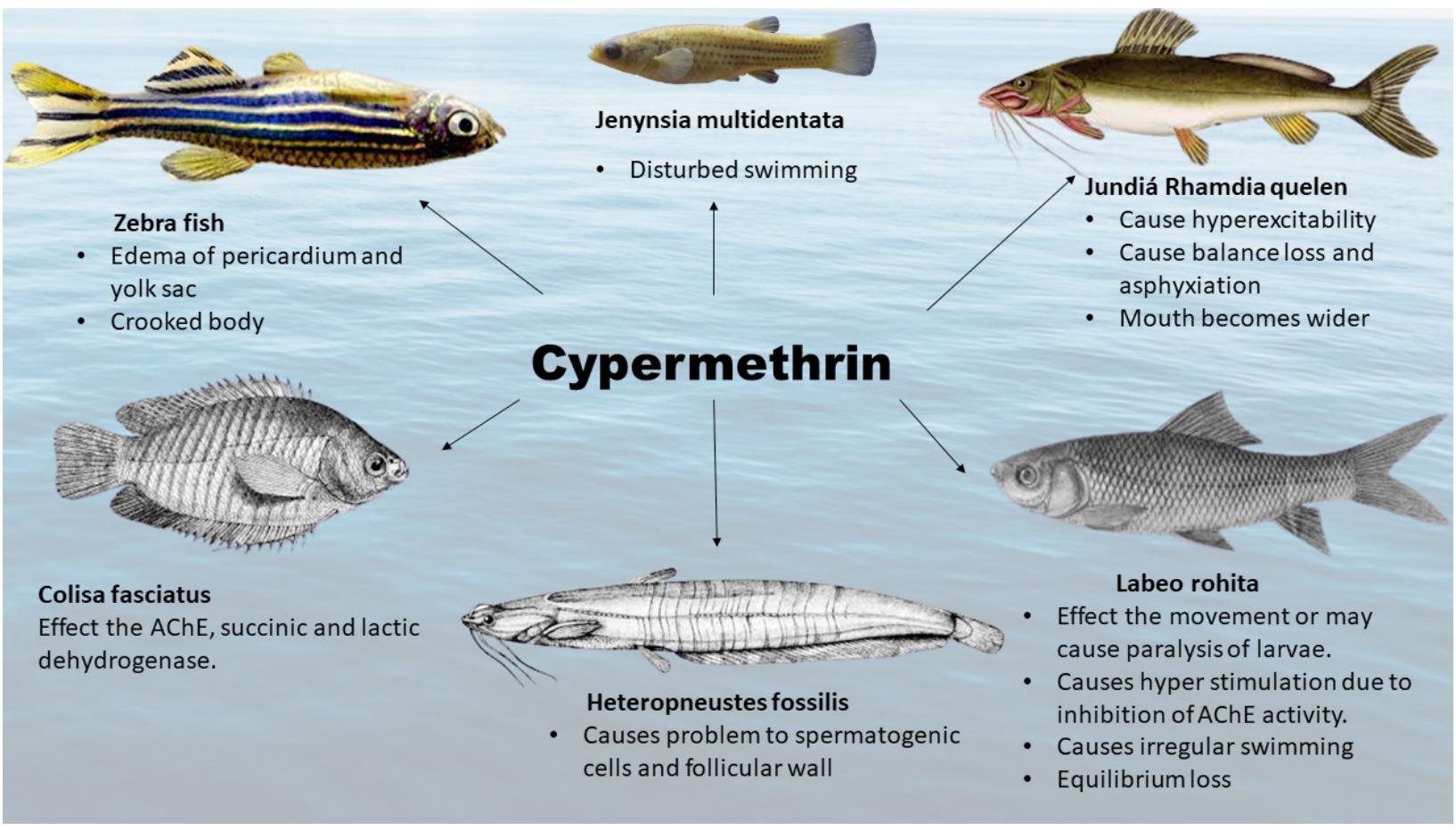

Fig. 1: Effect of cypermethrin on aquatic life. 
notable reduction was observed in activities of catalase and level of GSH in the liver and gills, on the other hand, there was an increase in LPO in both the tissues (Ansari \& Ansari 2014). The cypermethrin effect differently on the larvae than on the embryo of Gangetic mystus. In Mystus cavasius the hatching rate is decreased and larvae mortality is increased significantly due to increased concentration of cypermethrin. When exposed to high cypermethrin concentrations, different abnormalities occur in embryos and larvae. The observed abnormalities in larvae were edema and notochord fracture when exposed to various concentrations of cypermethrin. All these malfunctioning in Mystus cavasius embryo and larvae were due to high cypermethrin exposure (16 and 32 $\mu \mathrm{g} . \mathrm{L}^{-1}$ ) (Ali et al. 2018).

As per the studies, cypermethrin has the potential to control the secretion of HPG (hypothalamic-pituitary-gonadal) and similar hormones by channels of sodium $(\mathrm{Na})$ and calcium (Ca) (Ye et al. 2017). According to research conducted by (Zhang \& Li 2018) on zebrafish, beta-cypermethrin can damage its reproductive system. But, the mechanisms behind the toxicity caused by beta-cypermethrin in the fish reproductive system are not yet clear. It has been observed that due to beta-cypermethrin there is a huge reduction in the production of eggs. However, the mechanisms behind the toxicity caused by beta-cypermethrin in the reproductive system of fish are not yet clear. As shown in the study, beta-cypermethrin has the potential to minimize the reproductive capability of zebrafish. Even previous research has shown that beta cypermethrin significantly decreases the rate of pregnancy in female rats, suggesting that beta cypermethrin can harm the mammalian reproductive organs (Zhou et al. 2018a, 2018b).
The study concluded that beta cypermethrin could potentially target both fish and mammalian reproductive systems.

\section{Toxicity of Cypermethrin on Terrestrial Life}

Data signified that cypermethrin interfered with the energy transformation process in the same specimen. Cypermethrin has various effects in rats as mentioned in Fig 2. It shows the harmful impact on the reproductive system of male rodents. The androgen receptor and serum testosterone amounts were reduced significantly due to a regular dosage of 15 days. The study suggested the potent role of cypermethrin in initiating disfigurement of seminiferous tubules and adversely affecting spermatogenesis in male rodents at high dosages (Hu et al. 2011). Aside from the negative impact on males, (Zhou et al. 2018c) the likely role of beta-cypermethrin in inhibiting reproductive hormones and affecting female rats' fertility by blocking the endometrium, as well as, causing developmental delays in endometrial pinopodes was established. Due to daily cypermethrin exposure, dopaminergic neurodegeneration was initiated in rodents during their adulthood, while postpartum exposure increased the sensitivity of animals to dopaminergic neurodegeneration when challenged further in adulthood (Singh et al. 2012). Reports have also shown developmental delays in the progeny of rodents that were exposed to cypermethrin during pregnancy. The abnormal sperm count increased in male rodents due to exposure to cypermethrin. The experiment to investigate the potential impact on rat physiology of cypermethrin-treated lettuce, showed increased plasma concentrations of ALT, AST, and total biurubin and decreased plasma protein concentrations along with decreased body weight (Adjrah et al. 2013).

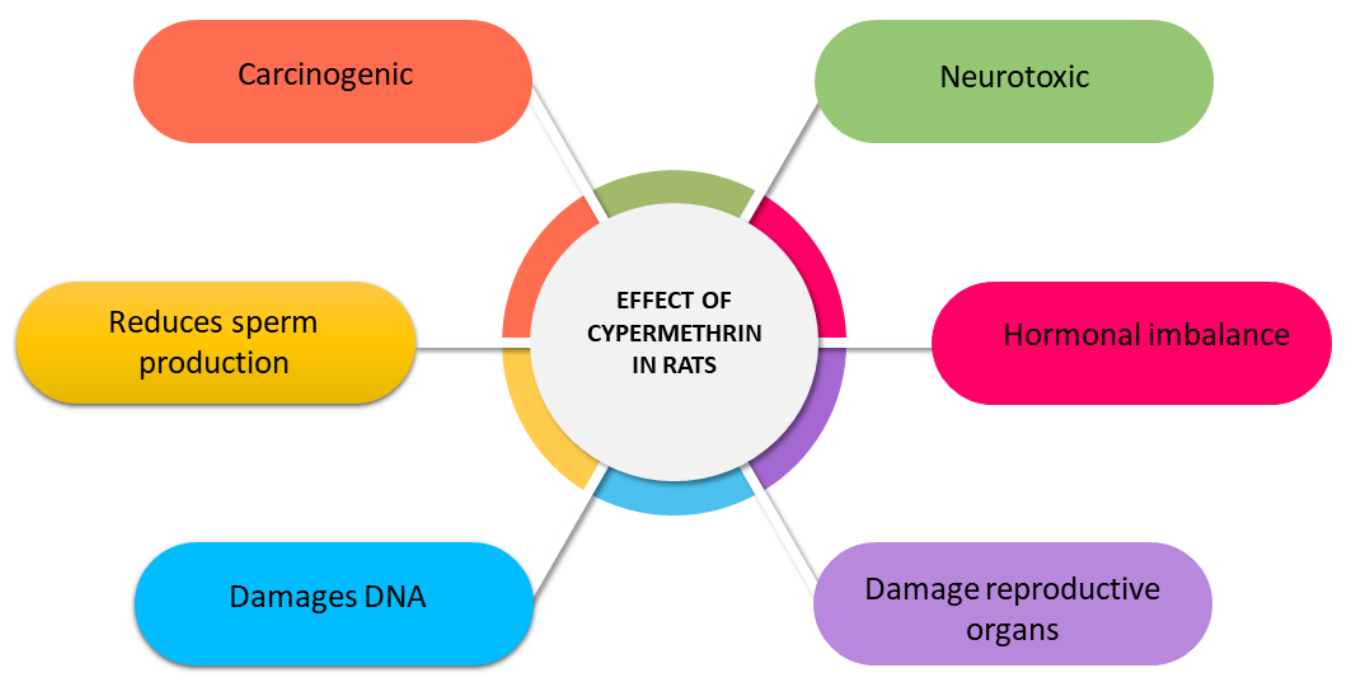

Fig. 2: Toxicological effect of cypermethrin in rats. 
In rats, 28 days of administration of cypermethrin resulted in a substantially increased number of micronuclei formation in bone marrow cells and dge ti DNA in blood cells (Sankar et al. 2010). Due to the combined effect of cytotoxic cytostatic, alpha-cypermethrin along with acetamiprid with different doses in human peripheral blood lymphocyte culture contribute to a substantial decrease in the mitotic, proliferation, and nuclear division indexes (Kocaman \& Topaktaş 2010). Exposure to cypermethrin contributes to follicular atresia by influencing angiogenesis pathologically, disrupting endocrine capacity, and increasing oxidative stress throughout the rat ovary (Molavi et al. 2016). Cypermethrin insecticide is neurotoxic in nature which acts on sodium $(\mathrm{Na})$, potassium $(\mathrm{K})$, and calcium $(\mathrm{Ca})$ channels for exerting neurotoxicity (Singh et al. 2012). In various papers, cypermethrin toxicity was reported to affect mammalian reproductive systems. According to studies, cypermethrin in male mice reduces the weight of reproductive organs, damages seminiferous tubules, decreased the production of sperms, and interferes with the hormone secretions (Huang \& Li 2014). In females, cypermethrin may reduce the follicle numbers and successful pregnancy rates by destroying the endometrium and may also disturb hormone secretions like estrogen and follicle-stimulating hormones (Sangha et al. 2013). Cypermethrin treatment in mice has shown a huge reduction in sperm count and testicular testosterone. The protein level in the testis was significantly reduced in cypermethrin-treated mice. An oral study in mice showed that cypermethrin induces neurotoxicity by damaging sciatic nerves, axonal degeneration by myelin sheet fragmentation, and axoplasm shrinkage (Kamel 2011).

The neurotoxicity data states the role of cypermethrin in damaging the ion channels (sodium, calcium, and chloride) of brain synaptosomes in rats. Also, recent data had shown that in mitochondrial membranes, the cypermethrin can damage the ion channels (Paravani et al. 2019, Kaisarevic et al. 2019, Gao et al. 2018). Currently, enough attention has been given to the impact of cypermethrin in reproductive organs. Cypermethrin subjection alters the amount of sex hormone in males, on the other hand, it has decreased reproductive production in females and triggers histopathological alterations in reptiles. Mitochondrial-associated apoptosis protein expression was estimated to find out the potential mechanism of apoptosis. Research to date has shown that pyrethroids have more harmful effects on vertebrates, affect the ion channels of the neuronal membrane and mitochondrial membrane (Lidova et al. 2016, Gao et al. 2018, Kaisarevic et al. 2019). Excessive cypermethrin use leads to the possibility of human exposure to many environmental pollutants (Romero et al. 2015). It also has unnecessary side effects on the non-targeted species, involving vertebrates (Vardavas et al. 2016).
Cypermethrin raises serum glucose in rats and drops the levels of serum triglycerides. The liver and kidney effects of cypermethrin have been studied in rats for both biochemical and histopathological effects (Sankar et al. 2012, Bhushan et al. 2013). As per the recent research done by Huang et al. (2018), it was discovered that exposure to cypermethrin can lead to metastasis of lung cancer by modulating macrophage polarization; cypermethrin treatment with macrophages has facilitated the growth of lung cancer cells in both in-vivo and in-vitro models. According to the findings, cypermethrin can inhibit M1 polarisation and enhance M2 phenotypes in macrophages, which is important for tumor metastasis.

\section{ADVANCE TECHNOLOGY USED FOR CYPERMETHRIN DETECTION}

Mostly cypermethrin degradation is studied by using gas chromatography, mass spectroscopy, and HPLC (Castellarnau et al. 2016). The most widely used methods for the identification of cypermethrin and its residues in various samples, such as crops, soil, and other samples depend on the extraction of the organic solvent residues. These methods are capable of detecting cypermethrin metabolites up to ng.gm-1 of soil, efficiently following microbial degradation (Braganca et al. 2018). HPLC is used for the quantification of cypermethrin. It is quick, easy, reliable, and has a low cost. Different types of detectors like UV and a photodiode are used for the detection of cypermethrin. During cypermethrin degradation, different metabolites are produced which can be observed by using GC-MS analysis. Each degraded metabolite is represented by different peaks in the gas chromatogram and these techniques are used due to their high sensitivity; however, they are very expensive as well as tedious. Furthermore, these techniques are highly selective and sensitive, and they generally require elaborate procedures, costly, and time-consuming sample pretreatment steps. Traditional chromatography-based techniques, which need complicated sample preparation protocols, and experts, and specialized instruments, are being replaced by newer approaches like electrochemical sensors and optical sensors which reduce sample preparation costs and time and can allow on-site pesticide detection. Therefore, advanced technologies are invented which are highly accurate, simple, less time-consuming.

\section{Microfluidic Paper-Based Analytical Device}

A Microfluidic paper-based analytical device is used for the identification of type II pyrethroids present in various water samples, and the detection depends on the cyanide formation from the hydrolysis of type-II pyrethroid. This detection method comes up with an alternative way for 
rapid, semi-quantitative analysis of pesticide-contaminated samples by permitting low-cost testing, mobility, and low sample utilization. (Pengpumkiat et al. 2020)

\section{Electrochemical Sensing}

Various techniques are used for cypermethrin detection include HPLC, GC-MS, immunoassay, etc. (Zhou et al. 2018c). However, due to a few drawbacks, such as false-positive reactions, laborious pretreatment, high turnaround times, and high costs, it limits their uses (Li et al. 2016, Zhang et al. 2014). This helps scientists to find the latest and effective method for cypermethrin testing. Whereas electrochemical sensor has edge over other methods as it has simple preparation, low detection limit, high sensitivity, and convenient operation. As compared to the methods described above, trace analytes can be traced rapidly and instantly in a simple manner (Ng \& Khor 2017). Detection of cypermethrin from real samples was rapid and accurate with an electrochemical sensor. Different electrochemical sensors like DMMIP-Ag-N@ $\mathrm{ZnO} / \mathrm{CHAC}$ have immense capabilities in the detection of drug residues, food safety, and environmental detection $(\mathrm{Li}$ et al. 2019).

\section{Optical Sensing}

Intensive research is being conducted in the domains of optical sensing and pesticide monitoring in water. With the scarcity of freshwater, the development of these kinds of optical sensors is in high demand. Optical detection of pesticides has several benefits over other detection approaches since it uses simple routes and does not require complex equipments or environmental limitations. Taking into account the improvement of sensing process constraints such as sensitivity, selectivity, quick and adaptable approach for pesticide detection is of great importance to us. As a result, this method of identification and monitoring might be used to precisely monitor pesticides. Although there have been several reports on the detection of various pesticides, no or few attempts to produce optical sensor film as an analytical approach for pesticide detection have been made too far. Fluorescence, ultraviolet-visible, Raman, and chemiluminescence are some of the techniques used in optical sensors to investigate signal modifications. It consists of an identification element that interacts precisely with the target analyte, as well as a part of the transducer for signaling the interactions. Simple procedures, fast detection, wide linearity range, high sensitivity, simple operation, and cost-effectiveness are some of its advantages (Pang et al. 2016).

In contrast, the artificially manufactured molecularly imprinted polymer (MIP) is able to work as an excellent detecting option for the development of specialized sensing signals because of its special characteristics like simple manufacture, high stability, cost-effectiveness, and resistance to environmental effects (Capoferri et al. 2018, Zhang et al. 2018, Zhang et al. 2015). Electrochemical probes need electrical signal indicators for their functioning, however, MIP-based sensors are not dependent on the electrochemical activities of the analytes and hence have many applications. (Gupta et al. 2016, Li et al. 2018, Wei et al. 2017). Electrochemical polymerization is the most common approach for creating a molecularly imprinted electrochemical sensor, which allows for fine control of the polymer film thickness and produces a stable and consistent imprinted membrane. A single type of functional monomer is used in most MIP preparations (Li et al. 2016). According to research, MIPs made with multiple functional monomers outshines the performance of a single monomer (Wu et al. 2016), because of the integral function and combined effect that different monomers have on molecular recognitions. Because of the rise of polymer-template interaction groups and a variety of functional groups, selectivity and adsorption capacity of MIPs may be increased to some amount when properly chosen multi-monomers are associated with the generation of the polymeric skeleton (Geng et al. 2014, Zhao et al. 2017). MIPs nanoparticles were used as an alternative to antibodies in the fabrication of enzyme-linked immunosorbent assays since it was the simplest method. According to research by Xiao et al. (2016), MIP coat was applied to the surface of QDs to form MIP-QDs composites, which were used as sensing nanoparticles in the preparation of an ELISA like the technique for cypermethrin detection.

\section{CYPERMETHRIN DEGRADATION BY MICROORGANISMS}

In the detoxification and degradation of pesticides, microbes play a major role and the list of such microbes are listed in Table 1. The functional class of pesticides requires specific genes and enzymes to cleave them. The optimum environmental conditions are required for the functioning of microbes which helps in the effective biodegradation of pesticides (Chishti et al. 2013). The organic pollutants are degraded with help of microbial collaborations. Pseudomonas mendocina and P. putida strains have the ability to degrade cypermethrin up to $90 \%$ within 15 days (Mendoza et al. 2011). As reported by Chen et al. (2012), Streptomyces aureus HP-S01 can degrade $\beta$-cypermethrin and its 3-PBA metabolite from agricultural land. In the agricultural land, $80.5 \%$ and $73.1 \%$ of the dose of $\beta$-cypermethrin and 3PBA $\left(50 \mathrm{mg} \cdot \mathrm{kg}^{-1}\right)$ were removed from the sterile soil within 10 days. The elimination rate of beta-cypermethrin and 3-PBA in non-sterile soils was comparatively maximum $87.8 \%$ and 
Table 1: Different microorganisms involved in the degradation of cypermethrin.

\begin{tabular}{|c|c|c|c|c|}
\hline Microorganisms Name & Location & Intermediate products & Source & References \\
\hline Ochrobactrum lupini DG-S-01 & Zhongshan,China & 3-phenoxybenzoic acid & Activated sludge & Chen et al. (2011a) \\
\hline Bacillus sp. strain SG2 & Uttarakhand, India & $\begin{array}{l}\text { 3-phenoxybenzoic acid and } \\
\text { 3-phenoxybenzaldehyde }\end{array}$ & Soil & Sharma et al. (2016) \\
\hline Bacillus subtilis strain 1D & Uttarakhand, India & cyclododecylamine, phenol & Soil & Gangola et al. (2018) \\
\hline Bacillus thuringiensis strain SG4 & Uttarakhand, India & 3-phenoxybenzaldehyde & Soil & Bhatt et al. (2020) \\
\hline Bacillus sp. DG-02 & China & 3-phenoxybenzoic acid & Sewage treatment system & Chen et al. (2014) \\
\hline Bacillus thuringiensis strain ZS-19 & China & 3-phenoxybenzoic acid & Activated sludge & Chen et al. (2015) \\
\hline Azoarcus indigens strain HZ5 & Hangzhou, China & $\begin{array}{l}\text { 3-phenoxybenzoic acid and } \\
\text { 3-phenoxybenzaldehyde }\end{array}$ & Activated sludge & Ma et al. (2013) \\
\hline $\begin{array}{l}\text { Bacillus megaterium } \mathrm{JCm} 2 \text {, Rho- } \\
\text { dococcus } \mathrm{sp} \text {. } \mathrm{JCm} 5 \text { and Ochrobac- } \\
\text { trum anthropi } \mathrm{JCm} 1\end{array}$ & Punjab, India & $\begin{array}{l}\text { 3-phenoxybenzoic acid, cat- } \\
\text { echol, and phenol }\end{array}$ & Soil & Akbar et al. (2015) \\
\hline Streptomyces aureus strain HP-S-01 & Zhongshan, China & $\begin{array}{l}\alpha \text {-hydroxy-3-phenoxyben- } \\
\text { zeneacetonitrile } \\
\text { and 3-phenoxybenzaldehyde }\end{array}$ & Activated sludge & Chen et al. (2011c) \\
\hline Pseudomonas aeruginosa $\mathrm{CH} 7$, & China & $\begin{array}{l}3 \text { - ( } 2,2 \text { - d i c h l o r o e h te- } \\
\text { nyl)-2,2-dimethyl cyclopro- } \\
\text { panecarboxylic acid } \\
\text { and 3-phenoxybenzoic acid }\end{array}$ & Activated sludge & Zhang et al. (2011) \\
\hline $\begin{array}{l}\text { Catellibacterium sp. strain } \\
\text { CC-5 }\end{array}$ & Chengdu, China & $\begin{array}{l}\text { 3-phenoxybenzaldehyde } \\
\text { and } \alpha \text {-hydroxy-3-phenoxy- } \\
\text { benzeneacetonitrile }\end{array}$ & Soil & Zhao et al. (2013) \\
\hline Acinetobacter baumannii ZH-14 & Singapore & 3-Phenoxybenzaldehyde & Sewage sludge & Zhan et al. (2018) \\
\hline Aspergillus oryzae M-4 & China & $\begin{array}{l}\text { 3-Phenoxybenzoic acid, Phe- } \\
\text { nol, and Catechol }\end{array}$ & Soil & Zhao et al. (2016) \\
\hline Pseudomonas fulva $\mathrm{P} 31$ & Zhongshan, China & 3-Phenoxybenzaldehyde & Activated sludge & Yang et al. (2018) \\
\hline
\end{tabular}

79.3\% respectively. The bacterial strain CC5 was cultivated from polluted soil and identified as Catellibacterium sp. It utilizes cypermethrin as the primary source of carbon and degrades cypermethrin $\left(100 \mathrm{mg} \cdot \mathrm{mL}^{-1}\right)$ up to $97 \%$ within 7 days. The optimum degradation was at 30 temperature and $\mathrm{pH}$ 7. The cypermethrin elimination was higher in cypermethrin-treated soil inoculated with CC5 strain than in non-inoculated soil. This study shows that the bacterial strain can be used in the degradation of an environment contaminated with a pyrethroid (Zhao et al. 2013). According to Zhang et al. (2011), isolated Pseudomonas aeruginosa $\mathrm{CH}-7$ strain from activated sludge which utilizes cypermethrin as a carbon source for its growth was not able to degrade cypermethrin. Thus, the $\mathrm{CH} 7$ strain may have the ability to remediate the sewage and soil contaminated with cypermethrin. At 25-35 and $\mathrm{pH}$ of 7, the photosynthetic bacterium GJ-22 was able to degrade cypermethrin. Metabolic products were observed after performing gas chromatography-mass spectrometry, and degradation was done by oxidative and hydrolytic pathways producing 5 metabolites (Yin et al. 2012).
The SG4 strain of Bacillus thuringiensis has been isolated from the soil that degrades cypermethrin. SG4 has successfully degraded cypermethrin under various conditions. Degradation was greatly improved by bioaugmentation of cypermethrin-contaminated soil and strain SG4 (83.3\%). Degradation products research has resulted in the discovery of nine different cypermethrin metabolites, which demonstrates that cypermethrin can be degraded by binding its ester, then its benzene ring, and another metabolism (Bhatt et al. 2020). The isolated bacteria Bacillus subtilis strain $1 \mathrm{D}$ completely degrade cypermethrin within 15 days under laboratory conditions. The study indicated the action of the laccase enzyme in the degradation of cypermethrin. The isolated bacteria follow a metabolic pathway for detoxifying and degrading cypermethrin without any toxic metabolite. The isolated bacteria consume cypermethrin as a carbon source for their growth (Gangola et al. 2018). According to a study carried by (Narayanan et al. 2020), Bacillus cereus was isolated from BT cotton and soil contaminated with pesticide. $B$. cereus shows great resistance towards 
beta-cypermethrin at a concentration of $100 \mathrm{mg} . \mathrm{L}^{-1}$. First, by using thin-layer chromatography they confirmed the presence of beta-cypermethrin. SDS-PAGE analysis identified the pyrethroid hydrolase enzyme which was effective in metabolizing beta-cypermethrin. GC-MS analysis confirmed that Benzylamine and similar components were formed by beta-cypermethrin in degradation by B. cereus. As per the research on the degradation of cypermethrin by immobilization of Micrococcus sp. cells of strain CPN 1, PUF-immobilized cells have shown a higher degradation capability than other used matrices. PUF-immobilized cells could maintain the degradation capability after reusage for 32 cycles or more without losing their degradation capability (Tallur et al. 2015). Therefore, it could be used in the biodegradation of cypermethrin polluted water.

\section{CONCLUSION}

Cypermethrin insecticide is a type II pyrethroid that is broadly used in agricultural fields, and which contaminates the soil, water, and other environments. The toxicity of cypermethrin has recently been investigated in aquatic and terrestrial life. Therefore, cypermethrin degrading microbes were isolated and studied for many years for bioremediation. In the future, microorganisms that help in the decomposition of cypermethrin within a short period under various environmental conditions must be detected or isolated. The consortium-based approach to degrade pesticides is highly acceptable but cypermethrin degradation has not been significantly studied. Metagenomic techniques are time-saving compared to conventional culture-dependent strategies. The advancing omics-based technology will also promote the isolation and classification of contaminated sites of cypermethrin degrading microorganisms. It is a safe and efficient remediation technique that focused on cypermethrin residue contamination in natural environments.

\section{REFERENCES}

Adjrah, Y., Karou, S.D., Agbonon, A., Ameyapoh, Y. and Gbeassor, M. 2013. Effect of cypermethrin-treated lettuce (Lactuca sativa) on Wistar rat liver. J. Appl. Pharm. Sci., 3(1): 128-132

Agarwal, N. and Shahi, S.K. 2015. An environmental cleanup strategy-microbial transformation of xenobiotic compounds. Int. j. Curr. Micr. Appl. Sci., 4: 429-461.

Akbar, S., Sultan, S. and Kertesz, M. 2015. Bacterial community analysis of cypermethrin enrichment cultures and bioremediation of cypermethrin contaminated soils. J. Basic Microbiol., 55(7): 819-829.

Akinrotimi, O.A., Gabriel, U.U. and Ariweriokuma, S.V., 2012. Haematotoxicity of cypermethrin to African catfish (Clarias gariepinus) under laboratory conditions. J. Environ. Eng. Technol. 1 (2): 13-19.

Ali, M.H., Sumon, K.A., Sultana, M. and Rashid, H. 2018. Toxicity of cypermethrin on the embryo and larvae of Gangetic mystus, Mystus cavasius. Environ. Sci. Pollut. Res., 25(4): 3193-3199.
Ansari, S. and Ansari, B.A. 2014. Temporal variations of CAT, GSH, and LPO in gills and livers of zebrafish, Danio rerio, exposed to dimethoate. Arch. Polish Fish., 22(2): 101-109.

Bhatt, P., Huang, Y., Zhang, W., Sharma, A. and Chen, S. 2020. Enhanced cypermethrin degradation kinetics and metabolic pathway in Bacillus thuringiensis strain SG4. Microorganisms, 8(2): 223.

Bhushan, B., Saxena, P.N. and Saxena, N., 2013. Biochemical and histological changes in rat liver caused by cypermethrin and beta-cyfluthrin. Arh. Hig. Rada. Toksikol., 64, 57-67.

Braganca, I., Lemos, P.C., Barros, P., Delerue-Matos, C. and Domingues, V.F. 2018. Phytotoxicity of pyrethroid pesticides and their metabolite towards Cucumis sativus. Sci. Total Environ., 619-620, 685-691.

Capoferri, D., Álvarez-Diduk, R., Del Carlo, M., Compagnone, D. and Merkoçi, A. 2018. Electrochromic molecular imprinting sensor for visual and smartphone-based detections. Anal. Chem., 90(9), 58505856.

Castellarnau, M., Azcon, J.R., Lopez, J.F., Grimalt, J.O., Marco, M.P. and Nieuwenhuijsen, M.. 2016. Assessment of analytical methods to determine pyrethroids content of bednets. Trop. Med. Int. Health, 22: 41-51.

Chen, L., Xu, P., Diao, J., Di, S., Li, R. and Zhou, Z. 2016. Distribution, metabolism, and toxic effects of beta-cypermethrin in lizards (Eremias argus) following oral administration. J. Hazard. Mater., 306: 87-94.

Chen, S., Deng, Y., Chang, C., Lee, J., Cheng, Y., Cui, Z. and Zhang, L. H. 2015. Pathway and kinetics of cyhalothrin biodegradation by Bacillus thuringiensis strain ZS-19. Sci. Rep., 5(1): 1-10

Chen, S., Chang, C., Deng, Y., An, S., Dong, Y.H., Zhou, J. and Zhang, L.H. 2014. Fenpropathrin biodegradation pathway in Bacillus sp. DG-02 and its potential for bioremediation of pyrethroid-contaminated soils. J. Agric. Food Chem., 62(10): 2147-2157.

Chen, L., Guan, L.M., Wu, Y.N., Xu, L.J. and Fu, F.F. 2012. Study on the residue and degradation of fluorine-containing pesticides in Oolong tea by using gas chromatography-mass spectrometry. Food Control 25 : 433-440.

Chen S., Kaiping, L., Yanan, L., Meiying, H., Yanbo, Z. and Yong, Z. 2011a. Biodegradation of deltamethrin and its hydrolysis product3-phenoxybenzaldehyde by a newly isolated Streptomyces aureus strain HP-S-01. Appl. Microbiol. Biotechnol., 90: 1471-1483.

Chen, S., Hu, Q., Hu, M., Luo, J., Weng, Q. and Lai, K. 2011b. Isolation and characterization of a fungus able to degrade pyrethroids and 3-phenoxybenzaldehyde. Bioresour. Technol., 102(17): 8110-8116.

Chen, S., Hu, M., Liu, J., Zhong, G., Yang, L., Rizwan-ul-Haq, M. and Han, H. 2011c. Biodegradation of beta-cypermethrin and 3-phenoxybenzoic acid by a novel Ochrobactrum lupini DG-S-01. J. Hazard. Mater., 187(1-3): 433-440.

Chishti, Z., Hussain, S., Arshad, K.R., Khalid A. and Arshad, M. 2013. Microbial degradation of chlorpyrifos in liquid media and soil. J. Environ. Manage., 114: 372-380.

Dawar, F.U., Zuberi, A., Azizullah, A. and Khattak, M.N.K. 2016. Effects of cypermethrin on survival, morphological and biochemical aspects of rohu (Labeo rohita) during early development. Chemosphere, 144: 697-705.

Gangola, S., Sharma, A., Bhatt, P., Khati, P. and Chaudhary, P. 2018. The presence of esterase and laccase in Bacillus subtilis facilitates biodegradation and detoxification of cypermethrin. Sci. Rep., 8(1): 1-11.

Gao, Y., Kim, K., Kwon, D.H., Jeong, I.H., Clark, J.M. and Lee, S.H., 2018. Transcriptome-based identification and characterization of genes commonly responding to five different insecticides in the diamondback moth, plutella xylostella. Pestic. Biochem. Physiol., 144: 1-9.

Garoiaz, H., Berrabah, M., Elidrissi, A., Hammouti, B. and Ríos, A. 2012. Analysis of cypermethrin residues and its main degradation products in soil and formulation samples by gas chromatography-electron impact-mass spectrometry in the selective ion monitoring mode. International Journal of Environmental Analytical Chemistry, 92(12):1378-1388. 
Geng, H., Kong, S.F. and Wang, Y. 2014. NiS nanorod-assembled nanoflowers grown on graphene: morphology evolution and Li-ion storage applications. J. Mater. Chem. A, 2(36): 15152-15158.

Grewal, K.K., Sandhu, G.S., Kaur, R., Brar, R.S. and Sandhu, H.S., 2010. Toxic impacts of cypermethrin on behavior and histology of certain tissues of albino rats. Toxicol. Int., 17(2): 94-98.

Goswami, M.R., Pati, U.K., Chowdhury, A. and Mukhopadhyay, A. 2013. Studies on the effect of cypermethrin on soil microbial biomass and its activity in alluvial soil. Int. J. Agric. F. Sci., 3(1): 1-9.

Gupta, B.D., Shrivastav, A.M. and Usha, S.P. 2016. Surface plasmon resonance-based fiber optic sensors utilizing molecular imprinting. Sensors, 16(9): 1381.

Hu, J. X., Li, Y.F., Li J., Pan, C., He, Z., Dong, H.Y. and Xu L. C. 2011. Toxic effects of cypermethrin on the male reproductive system: With the emphasis on the androgen receptor. J. Appl. Technol., 54: 619-650.

Huang, C. and Li, X. 2014. Maternal cypermethrin exposure during the perinatal period impairs testicular development in C57BL male offspring. PLoS One, 9(5): e96781.

Huang, F., Chen, Z., Chen, H., Lu, W., Xie, S., Meng, Q. H. and Xia, D. 2018. Cypermethrin promotes lung cancer metastasis via modulation of macrophage polarization by targeting MicroRNA-155/Bcl6. Toxicol. Sci., 163(2): 454-465.

Jin, Y.X., Wang, L.G., Ruan, M., Liu, J.W., Yang, Y.F., Zhou, C., Xu, B. and $\mathrm{Fu}, \mathrm{Z}$.W. 2011a. Cypermethrin exposure during puberty induces oxidative stress and endocrine disruption in male mice. Chemosphere 84: $124-130$

Jin, Y.X., Zheng, S.S. and Fu ZW. 2011b. Embryonic exposure to cypermethrin induces apoptosis and immunotoxicity in zebrafish (Danio rerio). Fish Shellfish Immunol., 30: 1049-1054.

Johnson, M.S., Aubee, C., Salice, C.J., Leigh, K.B., Liu, E., Pott, U. and Pillard, D. 2017 A review of ecological risk assessment methods for amphibians: comparative assessment of testing methodologies and available data. Integr. Environ. Assess. Manage., 18: 91-114.

Kaisarevic, S., Tenji, D., Mihajlovic, V., Micic, B., Francija, E., Periz-Stanacev, J., Krnic Skiljo, B., Brkic, D. and Teodorovic, I. 2019. Comparative analyses of cellular physiological responses of non-target species to cypermethrin and its formulated product: contribution to the mode of action research. Environ. Toxicol. Pharmacol., 65: 31-39.

Kamel, A.M. 2011. Histologic study on the protective effect of $\alpha$-lipoic acid in sciatic nerve neurotoxicity induced by cypermethrin in albino rats. Egypt. J. Histol., 34(2): 218-230

Kocaman, A.Y. and Topaktaş, M. 2010. Genotoxic effects of a particular mixture of acetamiprid and $\beta$-cypermethrin on chromosome aberration, sister chromatid exchange, and micronucleus formation in human peripheral blood lymphocytes. Environ. Toxicol.: Int. J., 25(2): 157-168.

Kuivila, K.M., Hladik, M.L., Ingersoll, C.G., Kemble, N.E., Moran, P.W., Calhoun, D.L., Nowell, L.H. and Gilliom, R.J. 2012. Occurrence and potential sources of pyrethroid insecticides in stream sediments from seven US metropolitan areas. Environ. Sci. Technol., 4: 4297-4303.

Li, Y., Zhang, L., Dang, Y., Chen, Z., Zhang, R., Li, Y. and Ye, B. C. 2019. Robust electrochemical sensing of the molecularly imprinted polymer prepared by using bifunctional monomer and its application in detection of cypermethrin. Biosens. Bioelectron., 127: 207-214.

Li, Y., Liu, J., Zhang, Y., Gu, M., Wang, D., Dang, Y.Y. and Li, Y. 2018. A robust electrochemical sensing platform using carbon paste electrode modified with molecularly imprinted microsphere and its application on methyl parathion detection. Biosens. Bioelectron.,106: 71-77.

Li, Y., Song, H., Zhang, L., Zuo, P., Ye, B.C., Yao, J. and Chen, W. 2016. Supportless electrochemical sensor based on molecularly imprinted polymer-modified nanoporous microrod for determination of dopamine at trace level. Biosens. Bioelectron., 78, 308-314.

Lidova, J., Stara, A., Kouba, A. and Velisek, J. 2016. The effects of cypermethrin on oxidative stress and antioxidant biomarkers in marbled crayfish (Procambarus fallax f. Virginalis). Neuro. Endocrinol. Lett., 37(1): 53-59.

Ma, Y., Chen, L. and Qiu, J. 2013. Biodegradation of beta-cypermethrin by a novel Azoarcus indigens strain HZ5. J. Environ. Sci. Health B, 48(10): 851-859.

Macagnan, N., Rutkoski, C.F., Kolcenti, C., Vanzetto, G.V., Macagnan, L.P., Sturza, P.F. and Hartmann, M.T. 2017. Toxicity of cypermethrin and deltamethrin insecticides on embryos and larvae of Physalaemus gracilis (Anura: Leptodactylidae). Environ. Sci. Pollut. Res., 24(25): 20699-20704

Meenambal, M., Pugazhendy, K., Vasantharaja, C. and Venkatesan, S. 2012. Chelating properties of Delonix elata against cypermethrin induced oxidative stress and antioxidant enzyme activity in Cyprinus carpio (Linn). IJPBA., 3(1): 237-243.

Mendoza, J. C., Perea, Y. and Salvador, J. A. 2011. Bacterial biodegradation of permetrina and cipermetrina pesticides in a culture assemblage. Avances en Ciencias e Ingenieria, 2(3): 45-55

Molavi, M., Razi, M., Cheraghi, H., Khorramjouy, M., Ostadi, A. and Gholirad, S. 2016. Protective effect of vitamin E on cypermethrin-induced follicular atresia in rat ovary: Evidence for energy-dependent mechanism. Vet. Res. Forum, 7(2): 125.

Narayanan, M., Kumarasamy, S., Ranganathan, M., Kandasamy, S., Kandasamy, G. and Gnanavel, K. 2020. Enzyme and metabolites attained in degradation of chemical pesticides $\beta$ Cypermethrin by Bacillus cereus. Mater. Today, 64: 555-571.

Ng, K.L. and Khor, S.M. 2017. Graphite-based nanocomposite electrochemical sensor for multiplex detection of adenine, guanine, thymine, and cytosine: A biomedical prospect for studying DNA damage. Anal. Chem. 89(18): 10004-10012.

Pang, S., Yang T. and He, L. 2016 Review of surface-enhanced Raman spectroscopic (SERS) detection of synthetic chemical pesticides. TrAC Trends Anal. Chem., 85: 73-82.

Pankaj, G.N., Gangola, S., Khati, P., Srivastava, A. and Sharma, A. 2015. Optimization of sulfosulfuron biodegradation through response surface methodology using indigenous bacterial strain isolated from contaminated agriculture field. Int. J. Curr. Microbiol. Appl. Sci., 4: 105-112.

Paravani, E.V., Simoniello, M.F., Poletta, G.L. and Casco, V.H. 2019. Cypermethrin induction of DNA damage and oxidative stress in zebrafish gill cells. Ecotoxicol. Environ. Saf., 173: 1-7.

Pengpumkiat, S., Nammoonnoy, J., Wongsakoonkan, W., Konthonbut, P. and Kongtip, P. 2020. A microfluidic paper-based analytical device for type-II pyrethroid targets in an environmental water sample. Sensors, 20(15): 4107.

Pugazhendy, K., Meenambal, M. and Vijayan, P. 2012. Chelating property of Delonix elata against the toxic impact of cypermethrin on hematological changes in fresh fish Cyprinus carpio (Linn). J. Pharmacol. Res., 5(5): 2610- 2614

Raghavendra, K., Barik, T.K., Sharma, S.K., Das, M.K., Dua, V.K., Pandey, A., Ojha, V.P., Tiwari, S.N., Ghosh, S.K. and Dash, A. P. 2014. A note on the insecticide susceptibility status of principal malaria vector Anopheles culicifacies in four states of India. J. Vector Borne Dis., 51: 230- 234.

Raksheskar, G.A. 2012. Influenced of cypermethrin on DNA, RNA/ DNA ratio in gills of the freshwater fish Channa striata. Biol. Dis., 3(1): 17-19.

Romero, A., Ares, I., Ramos, E., Castellano, V., Martinez, M., Martinez-Larranaga, M.R., Anadon, A. and Martinez, M.A. 2015. Evidence for dose-additive effects of a type II pyrethroid mixture. In vitro assessment. Environ. Res., 138: 58-66.

Sankar, P., Telang, A.G. and Manimaran, A. 2010. Curcumin protects against cypermethrin-induced genotoxicity in rats. Environ. Toxicol. Pharmacol., 30(3): 289-291.

Sankar, P., Telang, A.G. and Manimaran, A. 2012. Protective effect of curcumin on cypermethrin-induced oxidative stress in Wistar rats. Exp. Toxicol. Pathol., 64(5): 487-493. 
Sangha, G.K., Kaur, K. and Khera, K.S. 2013. Cypermethrin induced pathological and biochemical changes in reproductive organs of female rats. J. Environ. Biol., 34(1): 99.

Sharma, A., Gangola, S., Khati, P., Kumar, G. and Srivastava, A. 2016. A novel pathway of cypermethrin biodegradation in a Bacillus sp. strain SG2 isolated from cypermethrin-contaminated agriculture field. 3 . Biotech, 6(1): 45.

Singh, R.N., Kumar, P., Singh, V.K. and Singh, D. K. 2010. Toxic effects of Deltamethrin on the levels of biochemical changes in the snail Lymnaea acuminata. J. Pharmacol. Res., 3(8): 1739- 1742.

Singh, A.K., Tiwari, M.N., Upadhyay, G., Patel, D.K., Singh, D., Prakash O. and Singh M.P. 2012. Long-term exposure to cypermethrin induces nigrostriatal dopaminergic neurodegeneration in adult rats: Postnatal exposure enhances the susceptibility during adulthood. Neurobiol. Aging, 33: 404-15.

State of Pesticide Regulations in India. 2013. Centre for Science and Environment, New Delhi.

Stephenson, R.R. 1982. Aquatic toxicology of cypermethrin. I. Acute toxicity to some freshwater fish and invertebrates in laboratory tests. Aqua. Toxicol., 2: 175-185.

Sushma, N. and Devasena, T. 2010. Aqueous extract of Trigonella foenum graecum (fenugreek) prevents cypermethrin-induced hepatotoxicity and nephrotoxicity. Hum. Exp. Toxicol., 29: 311-319.

Tallur, P.N., Megadi, V.B. and Ninnekar, H.Z. 2008. Biodegradation of cypermethrin by Micrococcus sp. strain CPN 1. Biodegradation, 19(1): 77-82.

Tallur, P.N., Mulla, S.I., Megadi, V.B., Talwar, M. P. and Ninnekar, H.Z. 2015. Biodegradation of cypermethrin by immobilized cells of Micrococcus sp. strain CPN 1. Braz. J. Microbiol., 46(3): 667-672.

Tendulkar, M. and Kulkarni, A. 2012. Cypermethrin-induced toxic effect on glycogen metabolism in estuarine clam, Marcia opima (Gmelin, 1791) of Ratnagiri Coast, Maharashtra. J. Toxicol., 6: 1-3.

Tripathi, G. and Singh, H. 2013. Impact of alphamethrin on biochemical parameters of Channa punctatus. J. Environ. Biol., 34(2): 227-230.

Vardavas, A.I., Fragkiadaki, P., Alegakis, A.K., Kouretas, D., Goutzourelas, N., Tsiaoussis, J., Tsitsimpikou, C., Stivaktakis, P.D., Carvalho, F. and Tsatsakis, A.M. 2016. Downgrading the systemic condition of rabbits after long-term exposure to cypermethrin and piperonyl butoxide. Life Sci., 145: 114-120.

Wei, Y., Zeng, Q., Bai, S., Wang, M. and Wang, L. 2017. Nanosized difunctional photo responsive magnetic imprinting polymer for electrochemically monitored light-driven paracetamol extraction. ACS Appl. Mater. Interfaces, 9(50): 44114-44123.

WHO Recommended Classification of Pesticides by Hazard 1994-95, WHO, Geneva.

Wu, L., Liu, F., Wang, G., Guo, Z. and Zhao, J. 2016. Bifunctional monomer molecularly imprinted polymers based on the surface of multiwalled carbon nanotubes for solid-phase extraction of tartrazine from drinks. RSC Adv., 6(1): 464-471.

Xiao, T.T., Shi, X.Z., Jiao, H.F., Sun, A.L., Ding, H., Zhang, R.R. and Chen, J. 2016. Selective and sensitive determination of cypermethrin in fish via enzyme-linked immunosorbent assay-like method based on molecularly imprinted artificial antibody-quantum dot optosensing materials. Biosens. Bioelectron., 75: 34-40.

Yang, J., Feng, Y., Zhan, H., Liu, J., Yang, F., Zhang, K. and Chen, S. 2018. Characterization of a pyrethroid-degrading Pseudomonas fulva strain P31 and biochemical degradation pathway of D-phenothrin. Front. Microbiol., 9: 1003.

Ye, X., Li, F., Zhang, J., Ma, H., Ji, D., Huang, X., Curry Jr., T.E., Liu, W. and Liu, J. 2017. Pyrethroid insecticide cypermethrin accelerates pubertal onset in male mice via disrupting the hypothalamic-pituitary-gonadal axis. Environ. Sci. Technol., 51 (17): 10212-10221.

Yin, L., Li, X., Liu, Y., Zhang, D., Zhang, S. and Luo, X. 2012. Biodegradation of cypermethrin by pseudomonas palustris GJ-22 isolated from activated sludge. Fresenius Environ. Bull. A, 21: 397-405.

Zhan, H., Wang, H., Liao, L., Feng, Y., Fan, X., Zhang, L. and Chen, S. 2018. Kinetics and novel degradation pathway of permethrin in Acinetobacter baumannii ZH-14. Front. Microbiol., 9: 98.

Zhang C., Wang S. and Yan Y. 2011. Isomerization and biodegradation of betacypermethrin by Pseudomonas aeruginosa $\mathrm{CH} 7$ with biosurfactant production. Bioresour. Technol., 102: 7139-7146.

Zhang, W., Li, B., Chen, L., Wang, Y., Gao, D., Ma, X. and Wu, A. 2014. Anal. Methods, 6 (7): 2066-2071.

Zhang, Y., Zhou, Y., Tang, Q., Hu, F., Feng, L., Shen, J. and Huang, B. 2018. The protective effects of selenium-enriched spirulina on the reproductive system of male zebrafish (Danio rerio) exposed to beta-cypermethrin. Food Funct., 9(11): 5791-5804.

Zhang, Y., Zuo, P. and Ye, B.C. 2015. A low-cost and simple paper-based microfluidic device for simultaneous multiplex determination of different types of chemical contaminants in food. Biosens. Bioelectron., 68: 14-19.

Zhang, Z. and Li, L. 2018. Efficient synthesis of molecularly imprinted polymers with bio-recognition sites for the selective separation of bovine hemoglobin. J. Sep. Sci., 41(11), 2479-2487.

Zhao H., Geng Y., Chen L., Tao K. and Hou T. 2013. Biodegradation of cypermethrin by a novel Catellibacterium sp. strain CC-5 isolated from contaminated soil. Can. J. Microbiol., 59: 311-17.

Zhao, J., Chi, Y., Xu, Y., Jia, D. and Yao, K. 2016. Co-metabolic degradation of $\beta$-cypermethrin and 3-phenoxybenzoic acid by co-culture of Bacillus licheniformis B-1 and Aspergillus oryzae M-4. PLoS One, 11(11): e0166796.

Zhao, W.R., Kang, T.F., Lu, L.P., Shen, F.X. and Cheng, S.Y. 2017. A novel electrochemical sensor based on gold nanoparticles and molecularly imprinted polymer with binary functional monomers for sensitive detection of bisphenol A. J. Electroanal. Chem., 786: 102-111.

Zhou, Y.J., Huang, H.R., Zhou, J. and Wang, L.Q. 2018a. Beta-cypermethrin exposure affects female reproduction by enhancing oxidative stress in mice uterine tissue. Regul. Toxicol. Pharmacol., 98: 284-290.

Zhou, Y.J., Wang, J.H., Wang, L.Q., Xiao, S., Wang, X.D., Yan, H.L., Li, C.F. and Zhu, H.Q. 2018b. Effect of beta-cypermethrin exposure on embryo implantation in mice. Reprod. Toxicol., 76: 1-11.

Zhou, J.W., Zou, X.M., Song, S.H. and Chen, G.H. 2018c. Quantum dots applied to methodology on detection of pesticide and veterinary drug residues. J. Agric. Food Chem., 66(6): 1307-1319. 